\title{
ENHANCEMENT OF HEAT TRANSFER RATE IN A FALLING FILM LAYER BY ULTRASONIC IRRADIATION
}

\author{
SEICHI DEGUCHI*, Hitoki MATSUDA*, MASANOBU \\ HASATANI*, \\ Department of Energy Engineering \& Science, Nagoya University, \\ Nagoya 464-01, Japan TEL: 052-789-3383 FAX: 052-789-5946 \\ YOSHINORI IMAMURA** \\ Chiyoda Corporation, 12-1, Tsurumi-cho, Tsurumi-ku, Yokohama \\ 230, Japan TEL: 045-521-1231 FAX: 045-506-1475 \\ MASANORI SATO $* * *$ \\ Honda Electronics Co., Ltd., 20, Oyamazuka, Toyohashi 441-31, \\ Japan TEL: 0532-41-2511 FAX: 0532-41-2093
}

Key Words: Heat Transfer Enhancement, Falling Film Layer, Sound Pressure, Ethylene Glycol, Ultrasonic Wave Irradiation

\begin{abstract}
This study is concerned with enhancing the heat transfer rate in a falling film layer of ethylene glycol on an inclined rectangular tray by applying ultrasonic waves irradiated from the bottom of the tray. The heat transfer coefficient in a falling film layer of ethylene glycol was determined by the measured temperature distributions under various conditions of liquid flow rate, power supplied to an ultrasonic vibrator and frequency of the ultrasonic wave. The evaporation rate of water from a falling film of ethylene glycol/water mixture was also measured.

As a result, the enhancing effect of ultrasonic irradiation on the heat transfer coefficient was obtained with increasing liquid flow rate. It was found that ultrasonic irradiation of $23.6 \mathrm{kHz}$ was more effective to enhance the heat transfer rate in a falling film layer than $46.9 \mathrm{kHz}$ ultrasonic waves. The heat transfer coefficient in a falling film layer was increased by ultrasonic irradiation in the order about $30 \%$, which was obtained at a film Reynolds number of 50.0 by using $23.6 \mathrm{kHz}$ ultrasonic waves. It was recognized that ultrasonic waves increased the evaporation rate of water in a falling film of ethylene glycol/water mixture.
\end{abstract}

\section{Introduction}

A falling film layer is an effective technique, especially for evaporators and regenerators in absorption heat pumps. There remains an urgent demand for further improving the heat transfer and heat exchange rates in the falling film layer. Different techniques have been proposed for the enhancement of heat and mass transfer rates in a falling film layer, such as using a finned pipe (Hijikata $e t$ al., 1991), a grooved pipe (Isshiki and Ogawa, 1991, Isshiki et al., 1991), and by applying an electro-hydro-dynamic effect (EHD) (Yamashita et al., 1992, Yamashita et al., 1993) or a marangoni effect (Kashiwagi et al., 1991, Kashiwagi et al., 1992).

The ultrasonic wave has peculiar physical effects such as cavitation and sound effects, which lead to enhancement of reaction rate in some kinds of liquid-phase reactions. It has been reported that heat transfer in forced flow and boiling heat transfer are enhanced by ultrasonic irradiation in the order of 40 and $100 \%$, respectively. However, experimental investigations to apply ultrasonic irradiation to heat transfer enhancement in a falling film layer seem rather rare.

\footnotetext{
* Received November 11, 1994. Correspondence concerning this article should be addressed to T. Kinugasa.
}

In this study, a falling film layer of ethylene glycol was formed on an inclined stainless-steel rectangular tray to which an ultrasonic vibrator was attached at the bottom. The film thickness, the sound pressure and the temperature distributions in a falling film layer were measured by changing the liquid flow rate, the supplied power and the frequency of the ultrasonic wave. The heat transfer coefficient was determined by measurement of the temperature in the falling film layer. The evaporation rate of water from a falling film of ethylene glycol/water mixture was also measured. The effect of ultrasonic irradiation on enhancement of the heat transfer and evaporation rates in a falling film layer was discussed.

\section{Experimental}

Figure 1 shows a schematic drawing of the experimental apparatus employed. A falling film layer is formed on a rectangular stainless-steel tray that measures $80 \mathrm{~mm}$ in width, $900 \mathrm{~mm}$ in length, $2 \mathrm{~mm}$ in thickness and is inclined at $10^{\circ}$. The side walls and the bottom of the tray are insulated with fiberglass. At a position $650 \mathrm{~mm}$ from the inlet of the test section, a PZT ultrasonic vibrator (composition: $\mathrm{Pb}\left(\mathrm{Zr}_{0.53} \mathrm{Ti}_{0.47}\right) \mathrm{O}_{3}$, diameter: $45 \mathrm{~mm}$, 


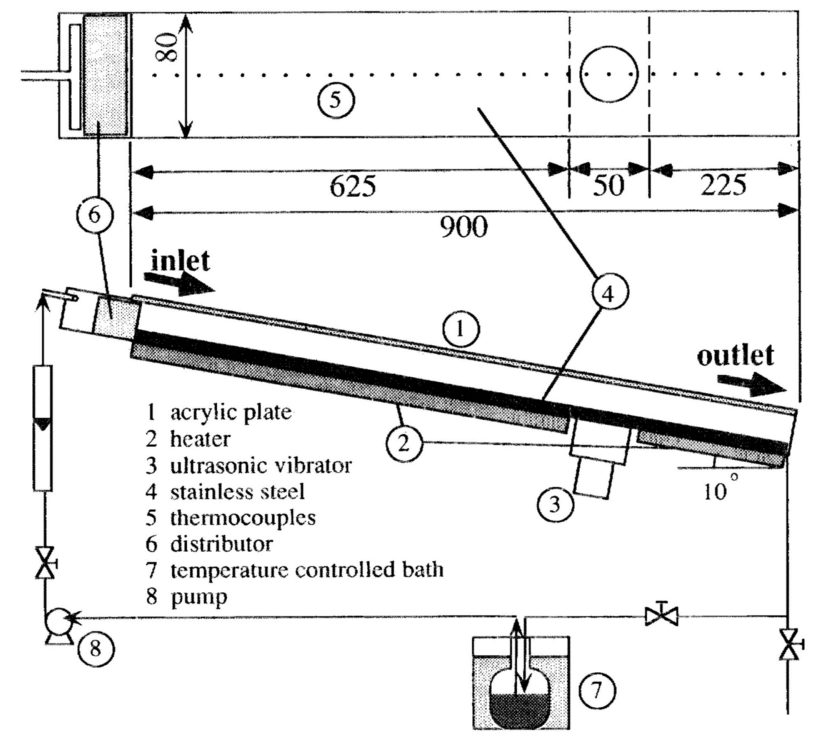

Fig. 1 Schematic drawing of experimental apparatus

frequencies: 23.6 and $46.9 \mathrm{kHz}$ ) is attached at the bottom of the tray. An electric heater is also set at the bottom of the tray, excluding the area where the ultrasonic vibrator is attached. The power supplied to the heater is controlled at about $2.0 \mathrm{~kW} / \mathrm{m}^{2}(130 \mathrm{~W})$.

In the heat transfer experiments, pure ethylene glycol was used as a test liquid. Ethylene glycol/water mixture having an initial concentration of $50 \%$ was used in the evaporation experiments. The test liquid was preheated in a temperature controlled bath and pumped from the reservoir to the upper side of the tray. The liquid flow rate was regulated by a needle valve and measured by a calibrated flow meter. The liquid was fed to the test section through a sponge distributor, and the corresponding film Reynolds number was set at more than 15.0 so as to form a uniformly distributed film flow on the whole test section.

All the experiments were carried out under atmospheric conditions. The sound pressure was measured by a sound pressure sensor inserted at a height of $0.5 \mathrm{~mm}$ from the plate surface. The temperature distribution in the falling film layer was measured by K-thermocouples of $0.1 \mathrm{~mm}$ in diameter set by the micrometers that are inserted from the upper surface of the falling film layer. The surface temperature of the heating plate was measured by K-thermocouples buried in the plate at the prescribed positions with an interval of $30 \mathrm{~mm}$. The bulk temperature of the test liquid was also measured. The heat transfer coefficient was determined from the measured temperature in the falling film layer. The evaporation rate of water was determined by measuring the concentration change in the test liquid. The concentration of ethylene glycol/water mixture was measured with an Abbe refraction meter at the outlet of the test section.

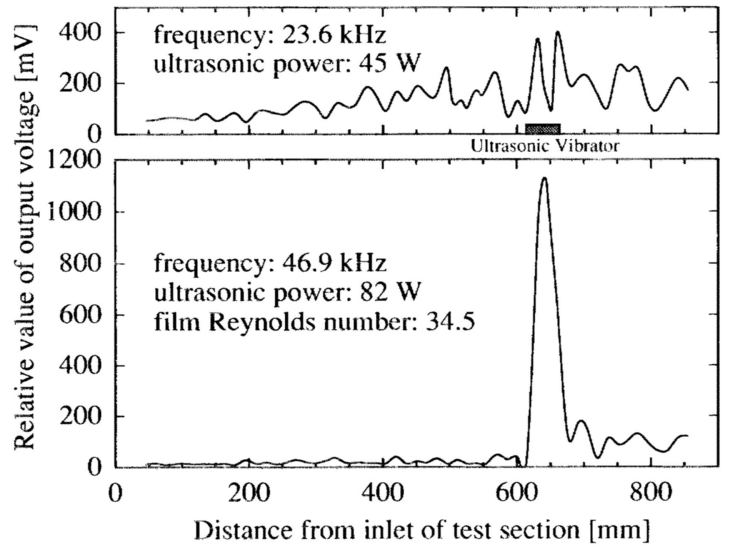

Fig. 2 Sound pressure distribution

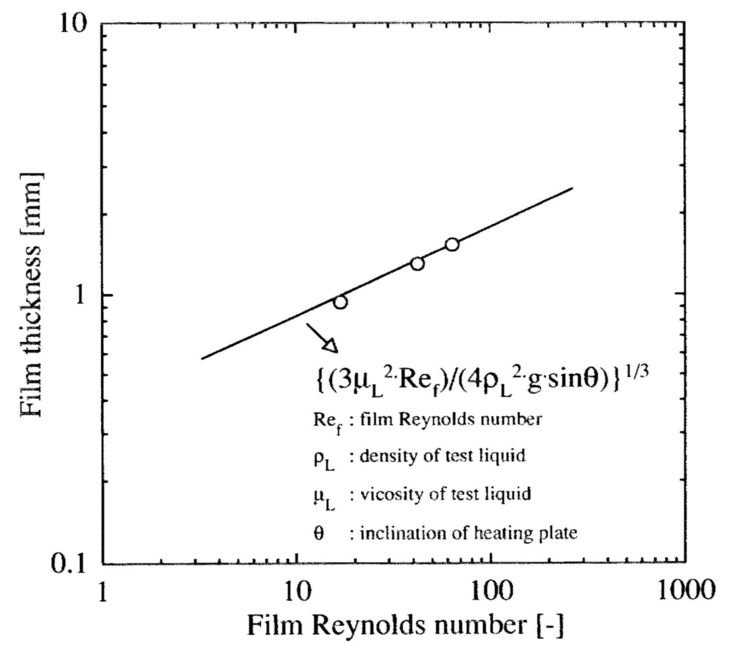

Fig. 3 Effect of film Reynolds number on film thickness

\section{Experimental Results and Discussion}

\subsection{Sound pressure distribution}

Figure 2 shows typical examples of the sound pressure distribution in a falling film layer of ethylene glycol obtained with a constant film Reynolds number of 34.5. From this figure, it can be seen that the ultrasonic sound travels to the whole test section. A considerable difference in the sound pressure distributions between the two frequencies of 23.6 and $46.9 \mathrm{kHz}$ is observed. A relatively periodical sound pressure intensity is obtained on the whole test section when the ultrasonic wave frequency is $23.6 \mathrm{kHz}$. On the other hand a rather sharp and high peak of sound pressure is formed for $46.9 \mathrm{kHz}$ at the position where the ultrasonic vibrator is attached. This difference in sound pressure distribution is caused by the sound directivity.

\subsection{Film thickness}

Figure 3 shows the thickness of a falling film layer of ethylene glycol obtained without ultrasonic irradiation. The solid line represents the expected film thickness calculated by the prescribed equation in this figure (Fulford, 1964). It is seen that the measured value is in a good accordance with the calculated one. 


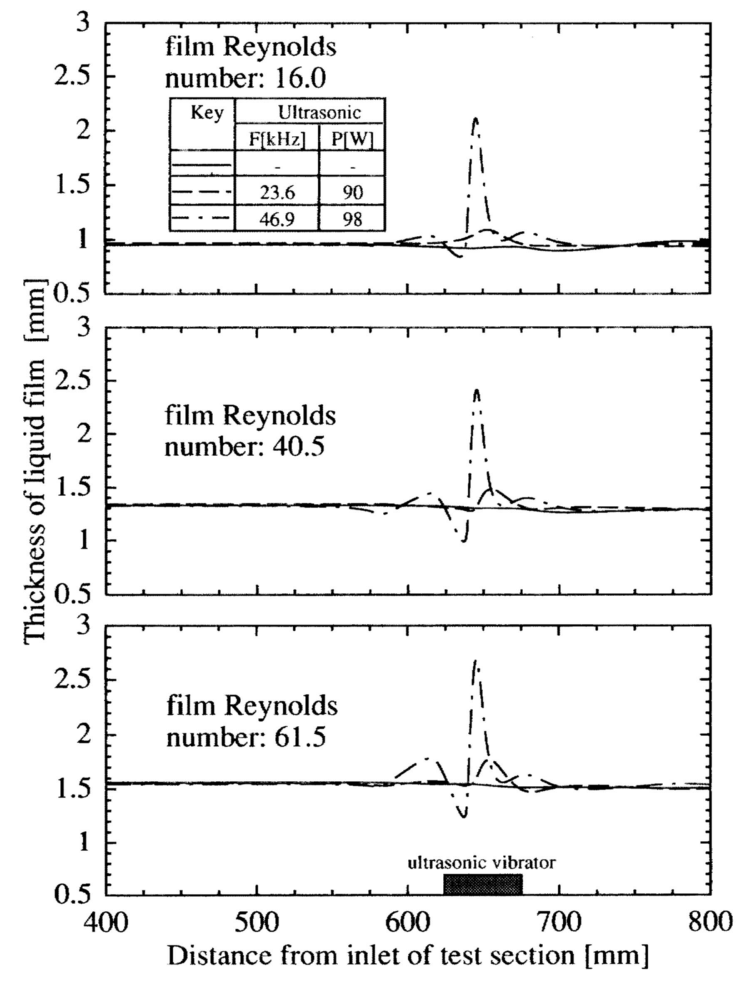

Fig. 4 Film thickness distribution

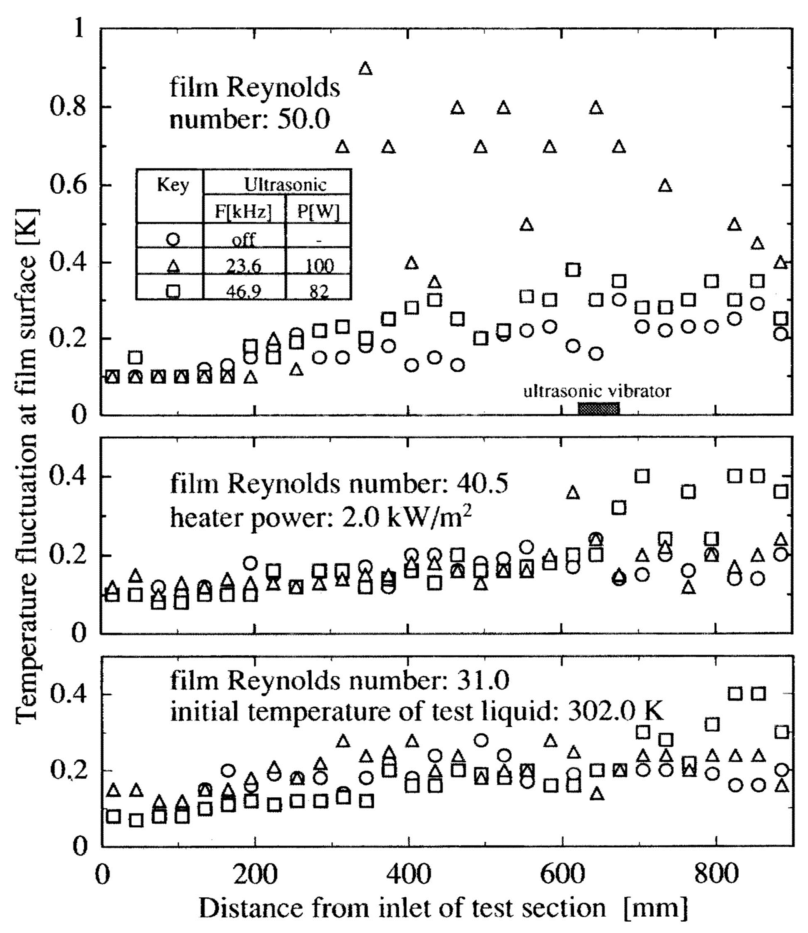

Fig. 5 Temperature fluctuation at film surface

Figure 4 shows the film thickness distributions around the position where the ultrasonic vibrator is attached with and without ultrasonic irradiation. It is seen from this figure that the thickness of the falling film layer is locally changed when the ultrasonic wave is irradiated, and the surface wave is formed on a falling film regardless of the ultrasonic frequency and the film Reynolds number.

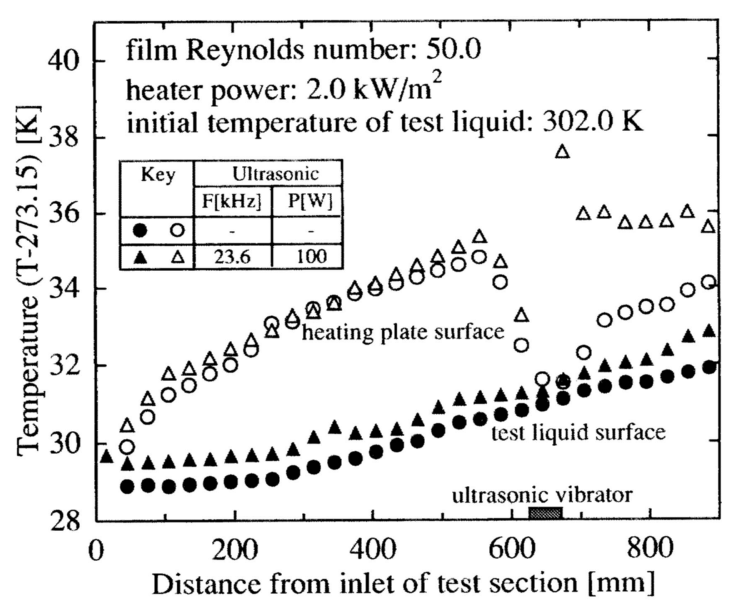

Fig. 6 Temperature distribution at heating plate surface and falling film surface

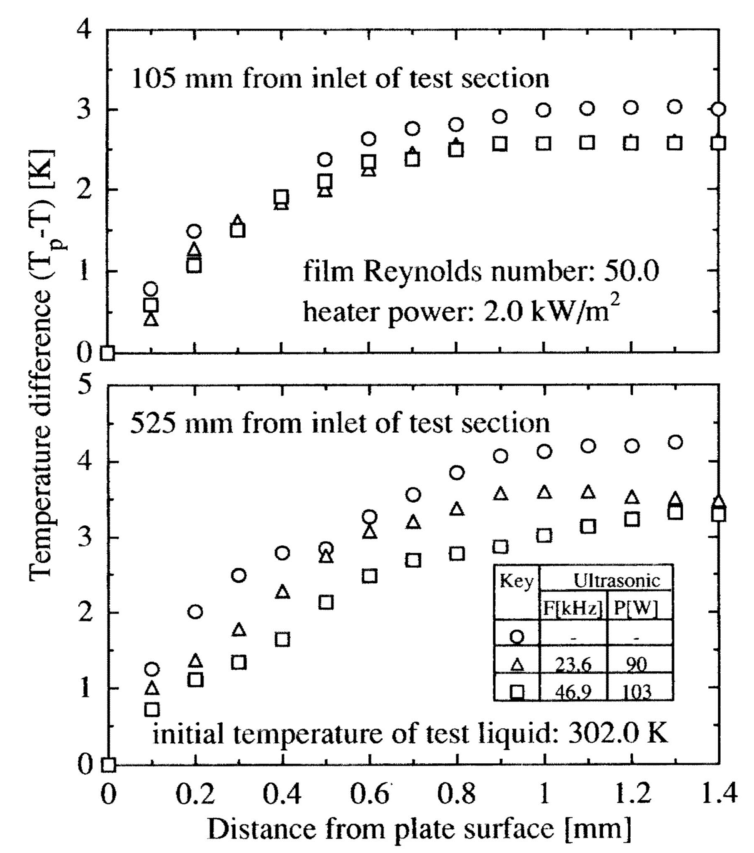

Fig. 7 Temperature distribution in film thickness direction

The profile of the film thickness depends on the ultrasonic wave frequency. For an ultrasonic wave frequency of 23.6 $\mathrm{kHz}$, the maximum increàse in film thickness, of about 0.2 $\mathrm{mm}$, is obtained at the position where the ultrasonic vibrator is attached. Little change in the film thickness is observed at other positions. For an ultrasonic wave frequency of $46.9 \mathrm{kHz}$, the film thickness increases to its maximum value of about $1.2 \mathrm{~mm}$ at the position where the ultrasonic vibrator is attached. The decrease in film thickness is observed exactly upstream of the position where the ultrasonic vibrator is attached. These differences in film thickness distribution may be caused by the difference of the sound pressure distribution in the falling film layer between 23.6 and $46.9 \mathrm{kHz}$.

\subsection{Temperature distribution in falling film}

Figure 5 shows the temperature fluctuation at a falling film surface obtained by changing the film Reynolds number and the ultrasonic wave frequency. It is seen that 


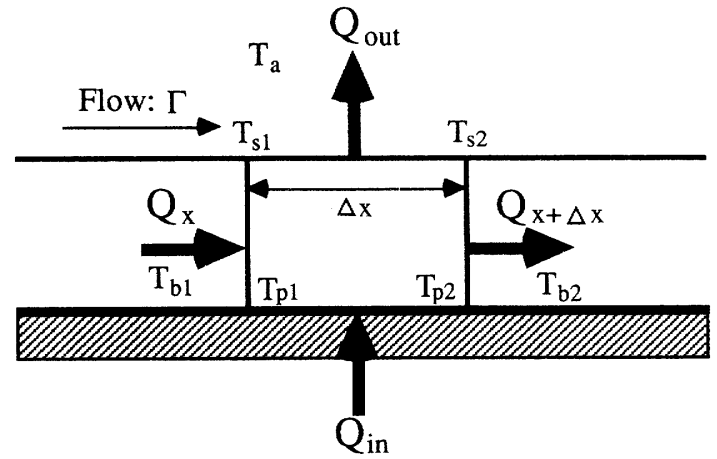

Fig. 8 Heat transfer system

the temperature fluctuation at the falling film surface is increased by ultrasonic irradiation with increasing film Reynolds number. In particular, a large temperature fluctuation was obtained at a film Reynolds number of 50.0 with ultrasonic irradiation of $23.6 \mathrm{kHz}$. It is considered to be caused by the ultrasonic wave disturbing flow structure in the falling film layer.

Figure 6 shows a typical example of the temperature distribution on a heating plate surface and in a falling liquid film surface in the flow direction obtained under a constant film Reynolds number of 50.0 with and without ultrasonic irradiation. It can be seen from this figure that the profiles of temperature distributions with ultrasonic irradiation are similar to those without ultrasonic irradiation in the upstream region from the position where the ultrasonic vibrator is attached. However, there is a considerable difference in the temperature profiles in the downstream region from the position where the ultrasonic vibrator is attached since additional heat is generated from the ultrasonic vibrator when the ultrasonic wave is irradiated. This may cause an error for estimation of the heat transfer coefficient in the case that the heat is transferred between the ultrasonic vibrator and the falling film layer. Moreover, the film thickness with ultrasonic irradiation is almost the same as that obtained without ultrasonic irradiation in the upstream region from the ultrasonic vibrator as is seen in Fig. 4. Therefore, the effect of ultrasonic irradiation on heat transfer coefficient in a falling film layer is discussed only for the upstream region from the ultrasonic vibrator.

Figure 7 shows the temperature distribution in the direction of the film thickness at positions of $105 \mathrm{~mm}$ and $525 \mathrm{~mm}$ from the inlet of the test section. The vertical axis represents the temperature difference between the heating plate surface and the measured position. It can be seen from this figure that the temperature difference measured at each position is decreased by ultrasonic irradiation. Thus, under this condition, it is expected that the heat transfer rate is increased by ultrasonic irradiation even in the upstream region from the position where the ultrasonic vibrator is attached.

\subsection{Heat transfer rate in falling film}

As depicted in Fig. 8, the heat transfer coefficient in a falling film layer is calculated by the following equation to estimate how the heat transfer rate is enhanced by ultrasonic irradiation.

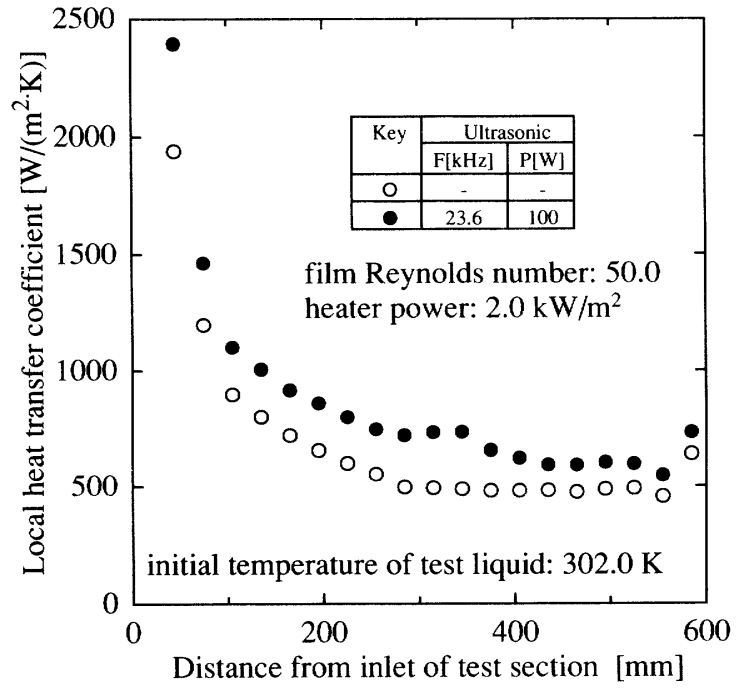

Fig. 9 Local heat transfer coefficient in falling film

$$
\begin{aligned}
& \mathrm{Q}_{\mathrm{X}}+\mathrm{Q}_{\text {in }}=\mathrm{Q}_{\mathrm{X}+\Delta \mathrm{X}}+\mathrm{Q}_{\text {out }} \\
& \mathrm{Q}_{\mathrm{X}}=\mathrm{C} \cdot\left(\mathrm{T}_{\mathrm{b} 1}-\mathrm{T}_{\text {in }}\right) \cdot \mathrm{w} \cdot \Gamma \\
& \mathrm{Q}_{\mathrm{X}+\Delta \mathrm{X}}=\mathrm{C} \cdot\left(\mathrm{T}_{\mathrm{b} 2}-\mathrm{T}_{\text {in }}\right) \cdot \mathrm{w} \cdot \Gamma \\
& \mathrm{Q}_{\text {out }}=\mathrm{h}_{\mathrm{a}} \mathrm{w} \cdot \Delta \mathrm{X} \cdot\left\{\left(\mathrm{T}_{\mathrm{s} 1}-\mathrm{T}_{\mathrm{a}}\right)+\left(\mathrm{T}_{\mathrm{s} 2}-\mathrm{T}_{\mathrm{a}}\right)\right\} / 2 \\
& \mathrm{Q}_{\text {in }}=\mathrm{h}_{\mathrm{f}} \mathrm{w} \cdot \Delta \mathrm{X} \cdot\left\{\left(\mathrm{T}_{\mathrm{p} 1}-\mathrm{T}_{\mathrm{s} 1}\right)+\left(\mathrm{T}_{\mathrm{p} 2}-\mathrm{T}_{\mathrm{s} 2}\right)\right\} / 2
\end{aligned}
$$

where $h_{f}$ is the local heat transfer coefficient between the heating plate and a falling film layer. $Q_{\text {in }}$ denotes the input heat flux from the heating plate. $\mathrm{Q}_{\text {out }}$ is the output heat flux released from the upper surface of a falling film to the air, and $h_{a}$ is the heat transfer coefficient between them. $Q_{x}$ and $Q_{x+\Delta x}$ represent the input and output heat flux of the liquid flow, respectively. Both $Q_{x}$ and $Q_{x+\Delta x}$ are determined from the measured bulk temperature of the test liquid.

Figure 9 shows the local heat transfer coefficient in a falling film layer with and without ultrasonic irradiation that is calculated from the measured temperature shown in Fig. 6. It is seen that the heat transfer coefficient decreases as the test liquid flows downwards, approaching a constant value at a position about $400 \mathrm{~mm}$ from the inlet of the test section. Comparing these constant values of the local heat transfer coefficient, it is recognized that the heat transfer rate is enhanced by ultrasonic irradiation in the order of about $30 \%$ under this condition.

Figure 10 shows the effect of ultrasonic irradiation on the Nusselt number obtained by changing the liquid flow rate and the frequency of the ultrasonic wave. It can be seen from this figure that the ratio of the Nusselt number with and without ultrasonic irradiation is larger than unity for a wave frequency of $23.6 \mathrm{kHz}$. The enhancing effect of ultrasonic irradiation on the heat transfer coefficient is obtained as the liquid flow rate is increased. However, when the ultrasonic wave frequency is changed to 46.9 $\mathrm{kHz}$, the heat transfer coefficient is decreased in some regions by ultrasonic irradiation. The heat transfer coeffi- 


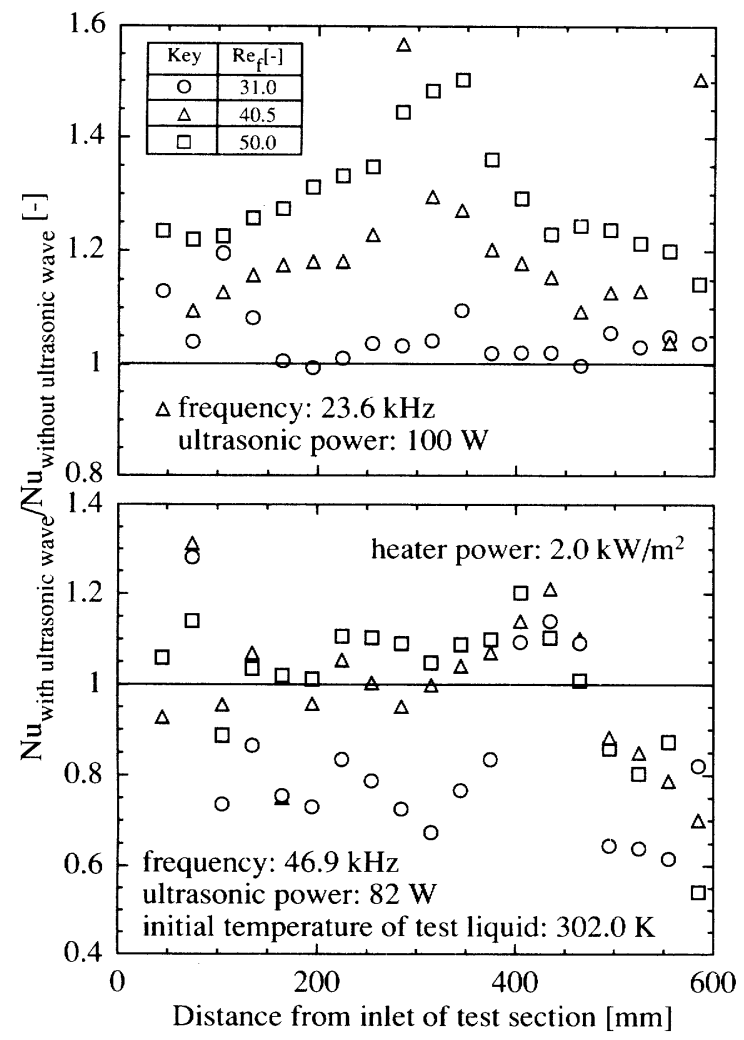

Fig. 10 Effect of ultrasonic irradiation on local Nusselt number

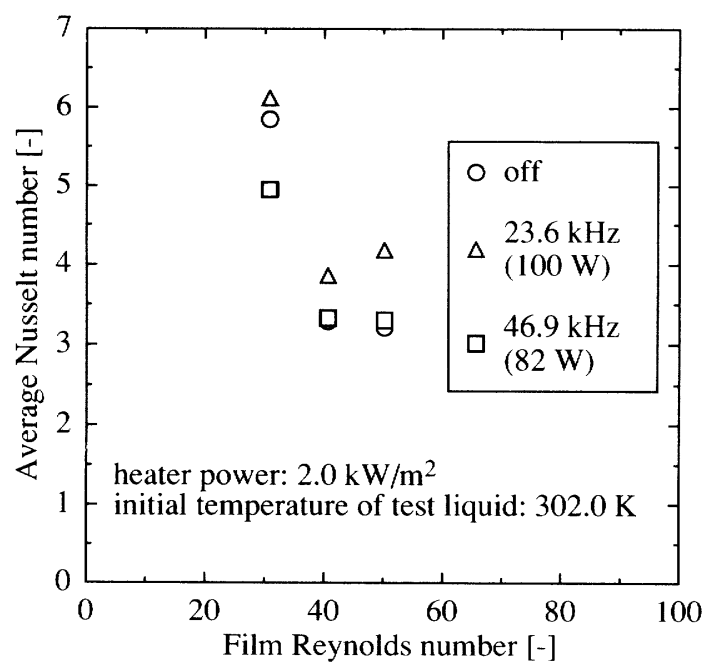

Fig. 11 Effect of film Reynolds number on average Nusselt number

cient near the ultrasonic vibrator is considerably decreased by ultrasonic irradiation, irrespective of the liquid flow rate. It was observed that small bubbles were formed in the vicinity of the plate surface of this region. It can be said that these bubbles decrease the heat transfer area and increase the heat transfer resistance between the heating plate and the falling film layer, resulting in a decrease in the heat transfer coefficient.

Figure 11 shows the average Nusselt number calculated from the local Nusselt number obtained at each measuring position in the test section. It is seen that ultra-

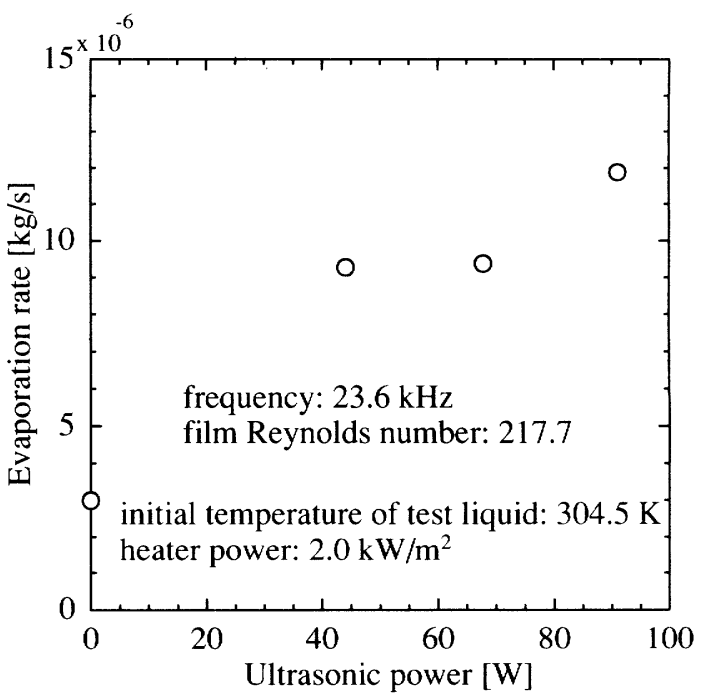

Fig. 12 Effect of ultrasonic irradiation on evaporation rate

sonic irradiation of $23.6 \mathrm{kHz}$ is more effective to get good heat transfer characteristics in the falling film layer.

\subsection{Evaporation rate from falling film}

Figure 12 shows the effect of ultrasonic irradiation on the evaporation rate of water from a falling film of ethylene glycol/water mixture. It is seen that the evaporation rate of water is considerably enhanced by ultrasonic irradiation and that the evaporation rate increases with an increase in the ultrasonic wave power. It is recognized that ultrasonic irradiation enhances the evaporation rate by a factor of almost four times that without ultrasonic wave under the same experimental conditions.

It is speculated that vibration, cavitation and other factors generated by the ultrasonic irradiation disrupt boundary layer flow of the falling film which leads to increse of heat and mass transfer rates. The existence of this phenomena is supported by the fact that a larger evaporation rate of water was obtained when a higher ultrasonic wave power was supplied.

\section{Conclusion}

Under the present experimental conditions, the heat transfer coefficient is increased by ultrasonic irradiation in the order of about $30 \%$ at a film Reynolds number of 50.0 for $23.6 \mathrm{kHz}$ ultrasonic waves. Ultrasonic irradiation of $46.9 \mathrm{kHz}$ is not so effective for enhancement of the heat transfer rate. This work clearly illustrates that ultrasonic irradiation can considerably enhance the evaporation rate of a falling film.

\begin{tabular}{|c|c|c|}
\hline \multicolumn{3}{|c|}{ Notation } \\
\hline$C$ & $=$ & heat capacity of test liquid \\
\hline$F$ & $=$ & ultrasonic wave frequency \\
\hline$g$ & $=$ & gravity \\
\hline$h_{a}$ & $=$ & $\begin{array}{l}\text { heat transfer coefficient between film surface and air } \\
\qquad\left[\mathrm{W} /\left(\mathrm{m}^{2} \cdot \mathrm{K}\right)\right]\end{array}$ \\
\hline$h_{f}$ & $=$ & $\begin{array}{l}\text { heat transfer coefficient between heating plate and } \\
\text { falling film } \\
{\left[\mathrm{W} /\left(\mathrm{m}^{2} \cdot \mathrm{K}\right)\right]}\end{array}$ \\
\hline$N u$ & $=$ & Nusselt number with ultrasonic irradiation \\
\hline$P$ & $=$ & ultrasonic wave power \\
\hline
\end{tabular}




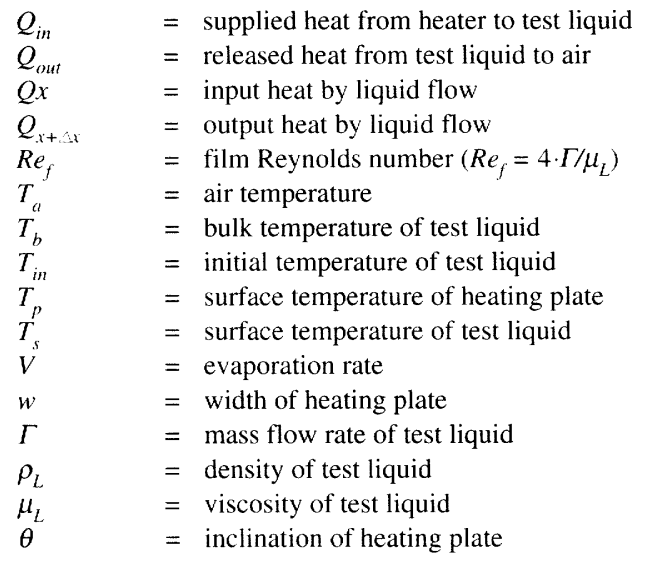

Literature cited

1) Fulford G. D.: Advances in Chemical Engineering, Academic

$[\mathrm{kg} /(\mathrm{m} \cdot \mathrm{s})]$

$\left[\mathrm{kg} / \mathrm{m}^{3}\right]$

$[\mathrm{kg} /(\mathrm{m} \cdot \mathrm{s})]$

$[\mathrm{rad}]$
Press, p. 157(1964)

2) Hijikata K., S. K. Lee and T. Nagasaki: Proc. of 28 th National Heat Transfer Symp. of Japan, D223, p.556-558(1991)

3) Isshiki N. and K. Ogawa: Proc. of 28 th National Heat Transfer Symp. of Japan, D213, p.544-546(1991)

4) Isshiki N., Y. Funato, K. Ogawa, N. Sasaki and H. Hashimoto: Proc. of 28th National Heat Transfer Symp. of Japan, D214, p.547$549(1991)$

5) Kashiwagi T., D. H. Rie, S. Kurosawa, T. Nomura and K. Omata: Transactions of the Japan Society of Mechanical Engineers, 57(539), p.2277-2284(1991)

6) Kashiwagi T., J. Okajima, Y. Asawa and S. Yamanaka: Transactions of the Japan Society of Mechanical Engineers, 58(556), p.36973702(1992)

7) Yamashita K., M. Kumagai, Y. Watanabe and A. Yabe: Proc. of 29th National Heat Transfer Symp. of Japan, F321, p.861-863(1992)

8) Yamashita K., M. Kumagai, Y. Watanabe and A. Yabe: Proc. of 30th National Heat Transfer Symp. of Japan, D21 1, p.598-600(1993) 